\title{
Temas y autores argentinos y latinoamericanos en proyectos editoriales de los exiliados gallegos en la Argentina durante la década del cuarenta
}

Topics and Argentine and Latin American Authors in Publishing Projects of the Galician Exiled in Argentina during the 40s

FEDERICO GERHARDT · federicogerhardt@gmail.com

Universidad NAGional de La Plata / CONICET(ARgENTINa)

Doctor en Letras por la Universidad Nacional de la Plata con una tesis sobre la trayectoria editorial de Max Aub en el exilio mexicano. Ha participado en proyectos de investigación sobre las relaciones culturales entre España y Argentina, con especial énfasis en el mundo editorial y la cultura de los exiliados.

RESUMEN: En el contexto de la época de oro de la industria editorial argentina, un grupo de exiliados de ascendencia gallega desempeñó un papel destacado a través de la edición de revistas culturales y de colecciones de libros: De Mar a Mar y Correo Literario, Buen Aire, Mar Dulce, Paloma y Botella al Mar. El presente trabajo analiza el lugar que ocuparon los temas y los autores latinoamericanos $-\mathrm{y}$, especialmente, argentinos- en esos proyectos editoriales, teniendo en cuenta las relaciones entre los exiliados y el campo cultural local.

Palabras Clave: Exilio español en Buenos Aires; historia de la edición; revistas literarias y culturales; Luis Seoane; Arturo Cuadrado.
ABSTRACT: In the context of the golden age of Argentina's publishing industry, a group of Galician exiles played a prominent role by publishing cultural magazines and book series: De Mar a Mar and Correo Literario, Buen Aire, Mar Dulce, Paloma and Botella al Mar. This paper analyzes the place occupied by the Latin American themes and the Latin American authors, especially Argentines, in these publishing projects, considering the relations between exiles and the local cultural field.

Palabras Clave: Spanish exile in Buenos Aires; publishing history; literary and cultural magazines; Luis Seoane; Arturo Cuadrado.

Gerhardt, Federico. "Temas y autores argentinos y latinoamericanos en proyectos editoriales de los exiliados gallegos en Argentina durante la década del cuarenta”. Kamchatka. Revista de análisis cultural 7

(Junio 2016): 73-96 DOI: 10.7203/KAM.7.7241 ISSN: 2340-1869 
La llegada de los exiliados de la Guerra Civil española y del franquismo a la Argentina, obstaculizada por el gobierno nacional a través de políticas migratorias restrictivas pero propiciada por redes de solidaridad con intervención de diversas organizaciones sociales (Schwarzstein 2001: 44-162), coincidió con el comienzo del "auge de la industria cultural” (Rivera 1998: 94) y, más específicamente, con los inicios de la conocida como "época de oro de la industria editorial" (De Diego 2006: 91), que se suele ubicar entre los años 1938 y 1955, aproximadamente. Se trata de una coyuntura favorable por el crecimiento del mercado del libro en la Argentina y por la caída de la industria editorial española como consecuencia de la Guerra Civil y la inmediata posguerra, que permitió no sólo que el libro argentino dominara el mercado interno sino también la expansión de las editoriales argentinas hacia el mercado externo (De Diego 2006: 103-105). Es en este periodo cuando se afianzan y desarrollan empresas editoriales comandadas, en muchos casos, por españoles residentes en Argentina, tales los casos de Sudamericana, por Antonio López Llausás, Emecé, por Mariano Medina del Río y Álvaro de las Casas, y Losada, por Gonzalo Losada (Pochat 1991, Larraz 2010 y 2011).

En este contexto propicio, la industria editorial constituyó un espacio de inserción laboral para gran cantidad de exiliados vinculados previamente al campo de la producción cultural. Es el caso del grupo de intelectuales y artistas de ascendencia gallega que tendrá un papel notable en el desarrollo de la edición en la Argentina, entre los que cabe destacar las figuras de Arturo Cuadrado, Lorenzo Varela y Luis Seoane, promotores de diversas empresas editoriales. ${ }^{1}$ En muchos casos, la trayectoria profesional en el mercado del libro argentino estará relacionada, no sólo con la ya referida situación favorable de la industria, sino también con el importante desarrollo de las entidades asociativas de ámbito gallego en Buenos Aires, determinado por las dimensiones de la inmigración procedente de Galicia en las dos últimas décadas del siglo XIX y, especialmente, las dos primeras del siglo XX (Rodino Lalín 1991:290). En este sentido, cabe señalar que las asociaciones étnicas gallegas sumaban a sus funciones asistenciales una dinámica labor cultural que cobra nuevo impulso a fines de la década del '30, con la llegada de los exiliados de la Guerra Civil española (Fernández Santiago 2001:182).

En términos generales, esta tarea cultural tiene como objetivos primordiales la difusión de la cultura gallega como cultura nacional diferenciada, y la promoción de una mayor comunicación entre los gallegos de la inmigración y de éstos con los de Galicia. Para este fin, además de la organización de conferencias, cursos, exposiciones, ferias y concursos, las distintas asociaciones de Buenos Aires desarrollaron una intensa labor editorial, entendida ella en sentido

${ }^{1}$ El grupo es a veces identificado como “la peña gallega del Tortoni” (González Ledo, 2008) o, simplemente, el “Grupo Tortoni” (Pérez Rodríguez, 2004), por el conocido café de la ciudad de Buenos Aires en que se reunía. 
amplio, es decir, tanto a través de la publicación de revistas, periódicos y boletines, como por medio de la edición de libros. ${ }^{2}$ A esta tarea se sumaron, con desigual fortuna, varios intentos editoriales particulares, siempre en el contexto propicio ya referido, también a la misma empresa de difusión de la cultura gallega, muchas veces promovidos por los mismos agentes. ${ }^{3}$ Sin embargo, al mismo tiempo e involucrando en ocasiones a los mismos agentes del campo editorial, se desarrollaron proyectos ya no sólo destinados a preservar y difundir la cultura gallega sino a estrechar lazos con la sociedad receptora. Es en este sentido que podrían considerarse ciertos proyectos editoriales promovidos en Buenos Aires por los mencionados exiliados de origen gallego durante los años 40, en los que tuvieron importante cabida las literaturas argentina y latinoamericana.

\section{La Editorial Emecéy su colección Buen Aire}

En el año 1939 se inicia la editorial Emecé, promovida por Mariano Medina del Río y Álvaro de las Casas, dos gallegos residentes en Buenos Aires, y financiada por la familia Braun Menéndez. Álvaro de las Casas habría sido el impulsor de la línea galleguista de la editorial (Devoto, 2012: 170), cuyos dos primeros libros formaron parte de la "Biblioteca Gallega", que reunía obras relacionadas con la cultura galaica en gallego o castellano, iniciada en ese mismo año con dos títulos: Santiago de Compostela, corazón de Europa, del propio De las Casas, e Historia de la cultura gallega de Ramón Otero Pedrayo. Al año siguiente, aparecería Aires da miña terra de Curros Enríquez.

En ese mismo año, 1940, se produce la entrada de Luis Seoane y Arturo Cuadrado a Emecé, donde comparten staff editorial con otros gallegos como Manuel Colmeiro, Eduardo Blanco-Amor y Rafael Dieste. Seoane y Cuadrado se desempeñarán en diferentes tareas, desde la lectura previa y selección de obras, el trabajo directo con la imprenta, la corrección de pruebas, e incluso la distribución (Pérez Rodríguez 2007: 36). Además, el propio Seoane se encarga del diseño y la diagramación de los libros hasta 1942, y de las ilustraciones de algunos de ellos,

2 Así, por ejemplo, podrían mencionarse entre muchos otros los casos del Boletín Oficial del Centro Gallego, luego rebautizado Galicia, y del sello Ediciones Galicia, ambos del mencionado Centro; o el periódico El Despertar Gallego -también rebautizado Galicia- y la Editorial Alborada, de la Federación de Sociedades Gallegas (Rodino Lalín 1989).

3 A modo de ejemplo, puede remitirse al caso de Luis Seoane, en cuya trayectoria editorial se observa la participación en proyectos de uno y otro tipo, procurando a veces conjugarlos, como en su inédito proyecto para un convenio entre la Editorial Losada y el Centro Gallego de Buenos Aires, para la creación de una "Biblioteca de Escritores Gallegos", fechable en 1939 y recientemente sacado a la luz (Gerhardt, 2015). 
Federico Gerdhart. Temas y autores argentinos...

aunque no siempre aparezca este trabajo reflejado en los créditos de los volúmenes (Pérez Rodríguez 2007 y 2009a).

Particularmente, la tarea más notable y más destacada por los estudios posteriores, desarrollada por Seoane y Cuadrado dentro de Emecé fue llevar adelante las colecciones Dorna y Hórreo, ambas de temas y autores gallegos. De Seoane son, asimismo, las marcas tipográficas de cada colección, y también las ilustraciones de tapa e interiores de la mayoría de los volúmenes. En el marco de la colección "Dorna”, destinada a la poesía, aparecieron obras como Rojo farol amante (1940) de Rafael Dieste, Queixumes dos pinos (1940) de Eduardo Pondal, Cantigas de Macías o namorado (1941), y el Cancionero popular gallego (1942) de José Pérez Ballesteros.

Los títulos reunidos en la colección "Hórreo", por su parte, presentaban una mayor variedad genérica, que incluye novelas, cuentos breves, leyendas populares y fundamentalmente ensayo histórico y filosófico, sobre todo pero no exclusivamente, de autores de los siglos XVIII y XIX, como Concepción Arenal, Rosalía de Castro, Emilia Pardo Bazán, Fray Martín Sarmiento, entre otros. A su vez, dentro de la misma colección, la llamada "Serie Blanca" guardaba lugar para los escritores españoles no gallegos, y en ella se publicaron El señor de Bembibre de Gil y Carrasco y Los sueños de Francisco de Quevedo.

Sin embargo, también en la misma editorial, Seoane y Cuadrado, en colaboración con Luis Baudizzone $^{4}$-años más tarde, fundador y director de la Editorial Argos-, crearon y desarrollaron, también en Emecé, la Colección Buen Aire, cuyo subtítulo aclaraba "Imágenes y espíritu de América". Se trataba, entonces, de un proyecto editorial diferente de Hórreo y Dorna, en este caso ya no enfocado en la cultura gallega sino mirando a la cultura del país y el continente receptores. En una entrevista posterior, declara Seoane:

Nosotros comenzamos en Emecé con una colección que se llamaba "Buen Aire", porque sólo el afán nuestro[,] de Cuadrado, Baudizzone y yo, que comenzamos los tres haciendo "Buen Aire", era el de hacer una pequeña colección de libros que fuesen muy bonitos, pero al mismo tiempo fuesen el reflejo de lo que era Latinoamérica. (2009: $167)^{5}$

En el aspecto material, los libros responden a los propósitos de la colección: se trata de joyas bibliográficas en pequeño formato y edición en cartoné. La marca tipográfica de la

\footnotetext{
${ }^{4}$ Y con José Luis Lanuza, según Pochat (1991).

5 En otra sección de la entrevista, Seoane, aunque sin mencionar a Cuadrado, insiste en la idea: "Yo fui amigo de Baudizzone, con quien hice una colección de libros, 'Buen Aire”’ (2009: 172).
} 
colección es también obra de Luis Seoane. ${ }^{6}$ En lo que respecta a su catálogo durante la participación en el proyecto de Seoane y Cuadrado, puede advertirse una considerable variedad de géneros que abarcan desde crónicas y libros de viaje hasta biografías y documentos, pasando por poesía, teatro, cuentos y leyendas, todos ellos con un denominador común: su relación con la cultura latinoamericana, fundamentalmente argentina y rioplatense, aunque también guardando un lugar a la brasileña. La colección se inicia en 1941 con Buenos Aires visto por los viajeros ingleses, a la que siguen ese mismo año Cancionero del tiempo de Rosas (selección de José Luis Lanuza), y Las Pampas, que incluye textos de José Hernández y otros autores argentinos.

$\mathrm{Al}$ año siguiente toma impulso y publica numerosos volúmenes, entre los que se cuentan: Cancionero de Manuelita Rosas (recopilación y notas de Rodolfo Trostiné, introducción de Miguel Cané), Los conversadores (selección de Luis Baudizzone), Floresta de leyendas rioplatenses (selección e introducción de Luis Aznar), Los morenos (selección de José Luis Lanuza), Retablo de Navidad. Cantares y villancicos (selección, prólogo y notas de Alberto Franco), El Norte de Bernardo Canal Feijóo, Médicos, magos y curanderos de Luis Gudiño Kramer, Mitos sobre el origen del fuego de James Frazer, Relación del primer viaje de Cristóbal Colón, Descubrimiento del Amazonas de Cristóbal de Acuña, Viaje al Río de La Plata de Ulrico Schmidl, Estados Unidos de Domingo Faustino Sarmiento, Autobiografía. Memorias sobre la expedición al Paraguay y batalla de Tucumán de Manuel Belgrano, y Bernardo O'Higgins: el padre de la patria chilena de Enrique Campos Menéndez. También en 1942 se publican dos libros cuya edición estará a cargo de Baudizzone, Cuadrado y Seoane: Lira romántica suramericana y Alôs Afro-Brasileños, del diplomático brasileño Newton Freitas.

Este breve repaso pone en escena que, tal como menciona en la entrevista Seoane, el catálogo se fija en "lo que era Latinoamérica" (el énfasis es mío), es decir, en su pasado, remontándose a tiempos precolombinos. De ahí también la fuerte presencia de material tradicional, folklórico y popular, además de los escritos de conquistadores, viajeros y próceres de la historia americana.

Este movimiento de apertura, desde las colecciones galleguistas a la Colección Buen Aire, que toma como objeto la cultura americana, es saludado, también en el exilio, por María Teresa León en febrero de 1942, en el artículo "Una editorial y su elogio", a propósito de Emecé,

\footnotetext{
${ }^{6}$ Para un análisis de los aspectos plásticos y de diseño de las ediciones de Emecé, Nova y Botella al Mar a cargo de Luis Seoane, v. el trabajo de Eugenia Costa (2014) que, aunque enfocado especialmente en el último de los casos mencionados, realiza un ilustrativo recorrido por los libros de los tres sellos.
} 
publicado en España Republicana -periódico del Centro Republicano Español en Buenos Aires-:

Comenzaron desentrañando la cultura gallega. Si tenemos en cuenta que una enorme masa emigrante de la costa de Galicia guarda su idioma de niñez entre cuatro recuerdos iniciales que cimentan la vida de todo hombre, era un acierto ofrecerles clasificada y en orden de buen gusto la literatura de aquella región de España [...] No sé hasta qué punto se han dado cuenta los gallegos que viven apresados en redes más inmediatas de afán, pero si un regalo pudieron depositar con orgullo en la cuna de su hijo, ya argentino, es esta colección de libros. [...] Pero he de añadir que las ediciones Emecé no se han detenido en el mundo cerrado de la literatura vernácula de los gallegos. [...] Han ensanchado su campo y han iniciado una colección sobre temas argentinos. (1942: 12)

En este sentido, la escritora considera la publicación de la colección Buen Aire como una iniciativa tendiente a estrechar lazos con la cultura receptora del exilio español, afirmando, en el citado elogio, que la misma "sirve de felicísimo emparejamiento de los trabajos de los escritores españoles en destierro con los que tan generosamente les hicieran lugar” (León, 1942: 12).

En el mismo año en que se publica el citado elogio, 1942, se produce la salida de Emecé por parte de Seoane y Cuadrado, por motivos no del todo esclarecidos ${ }^{7}$, no obstante lo cual la colección Buen Aire continuará su andadura en la línea iniciada en 1941, publicando numerosos volúmenes organizados en diversas series: "Viajes y Crónicas", "Poesía y Canciones”, "Paisajes y Ciudades", "Memorias y Recuerdos", "Leyendas y Folklore", "Temas y Documentos de Historia”, "Biografías", "Impresiones sobre América", "Teatro" y “Arte Americano".

\section{Las colecciones americanas de Nova: Mar Dulce}

Tras su salida de Emecé en 1942, Seoane y Cuadrado fundan en diciembre de 1942 la Editorial Nova, sello del que es parte también la Imprenta López con el 50\%, mientras que la

\footnotetext{
${ }^{7}$ En relación con la causa probable de la salida de Cuadrado y Seoane de Emecé, tres son las versiones que circulan: que se negaron a editar un libro del entonces embajador de la España franquista en la Argentina, que hicieron lo propio con una novela de Camilo José Cela, y que se solidarizaron con Lorenzo Varela ante los ataques recibidos por su militancia comunista. Señala Pérez Rodríguez, tras repasar estos tres motivos probables, que a ellos "se une que eran escasas las ventas de las obras de nuestros escritores o sobre nuestra Tierra, por lo que los resultados económicos tampoco jugaban a su favor" (2009a: 112). En igual sentido apunta De Diego, quien agrega ciertos detalles a esta hipótesis: "Parece ser, incluso, que la deserción de los dos gallegos de Emecé tuvo que ver con el giro de la editorial hacia la publicación de autores argentinos como Mallea y Borges, política a la que ellos se mostraban reticentes, ya que preferían continuar con la edición de textos de temática galleguista muy poco rentables" (2006: 99). En noviembre de ese mismo año, en la sección "Mercado de las artes y las letras", de Galicia, los dos editores gallegos publican una nota alegando una incompatibilidad moral.
} 
mitad restante se reparte en partes iguales entre los mencionados editores gallegos. ${ }^{8}$ Es precisamente en esos talleres en los que van a imprimirse todos los volúmenes de la editorial en el periodo abordado, volúmenes cuyo diseño, en todos sus aspectos, estará a cargo de Luis Seoane, como destaca Pérez Rodríguez:

Hasta 1947 el diseño de las marcas tipográficas, tapas, cubiertas y libros (que pueden estar en rústica y en tapa dura con cubierta) de Nova le incumbe a Luis Seoane, quien adapta las medidas de sus colecciones para no desperdiciar las resmas, no aprieta el espacio interlineal, compagina el tamaño, la redondez y grosor de la letra con las dimensiones de la página a la que adecua los blancos. (2013:120)

El catálogo que Nova va construyendo en el transcurso de los seis años en que la dirigen Luis Seoane y Arturo Cuadrado presenta ciertas continuidades con las iniciativas desarrolladas en el seno de Emecé. Es así que una de sus colecciones más emblemáticas sea Camino de Santiago, dedicada una vez más a la cultura gallega. La misma cuenta con once títulos, y se abre con Historias e invenciones de Félix Muriel, de Rafael Dieste. Las restantes entregas presentan textos de temas y/o autores gallegos (clásicos y contemporáneos), en su mayoría en idioma castellano, incluyendo títulos como Siervo libre de amor de Juan Rodríguez del Padrón (1943), Cuadros de la guerra de Concepción Arenal (1942), Don Diego Gelmírez de Manuel Murguía (1943) o Adolescencia de Ramón Otero Pedrayo (1944). Cabe destacar, en relación con Camino de Santiago, que su finalización se da de manera anticipada, en 1945, en lo que podría presumirse nuevamente como el resultado de escasos réditos económicos de una empresa enfocada en la difusión de la cultura gallega. ${ }^{9}$ Lo propio podría pensarse también de Pomba, la colección dedicada a la poesía y dirigida por Arturo Cuadrado, que contó con un solo volumen, Torres de amor de Lorenzo Varela (1942), antes de ser rebautizada y castellanizada como Paloma, para reorientar la conformación de su catálogo. A propósito, en carta a Fernández del Riego, del 6 de julio de 1951, Luis Seoane afirma:

Los únicos "mecenas" conocidos por mí en cuanto a problemas culturales gallegos, perdóname, somos Cuadrado y yo, que publicamos como hemos podido más de cincuenta libros gallegos en las colecciones "Hórreo", "Dorna", "Camino de Santiago"

y "Pomba", aunque a mí me quede mal decirlo y perdiendo en esta labor lo mejor de

\footnotetext{
${ }^{8}$ Según consta en la documentación económica obrante en los fondos documentales de la Fundación Luis Seoane (A Coruña).

${ }^{9}$ Circunstancia de la que dan prueba también otros proyectos frustrados aún antes de ver la luz, en años previo y posterior a las empresas aquí abordadas. V. Gerhardt (2015).
} 
Federico Gerdhart. Temas y autores argentinos...

nuestros años pues lo hicimos no sólo sin beneficio sino incluso sacando el dinero de otros trabajos para hacerlo. (FLS, 06/07/1951) ${ }^{10}$

Pero en Nova, la continuidad con respecto al proyecto editorial de Emecé no se reduce a las colecciones de temática o autores gallegos de escasa fortuna, sino que además está relacionada con la presencia de colecciones vinculadas con la cultura americana. En este aspecto del catálogo, se destaca la colección Mar Dulce.

Dirigida por Luis Baudizzone, la colección publicó una veintena de libros, impresos en formato octavo y con encuadernación en cartoné, cuyo diseño, a cargo también de Seoane, los dotaba de una clara identidad a partir de las cubiertas con un fondo de naipes. Años más tarde, y tal vez extremando su innovación, Seoane la recuerda como "la primera colección americana, posiblemente la primera colección americana que aparecía en ese momento en América, este... en general" (2009: 167). Lo cierto es que, más bien y como se ha dicho antes, la colección parecía continuar con el proyecto de Buen Aire.

En Mar Dulce se conjugan entonces textos diversos relacionados con la historia americana, remontándose nuevamente a tiempos precolombinos, dedicando la mayoría de los títulos a la cultura argentina pero dando también cabida a la del Brasil. Entre los volúmenes que componen su catálogo pueden mencionarse: Guamán Poma, prologado por Luis Baudizzone (1943); La calavera y otros grabados de Guadalupe Posada, prólogo de Luis Seoane (1943) ${ }^{11}$; Poesía, música y danza inca (1943); Amazonia. Leyendas Ñangatú, selección y noticia de Newton Freitas (1943); Poesía, música y danza inca, con selección y noticia de Baudizzone (1943); Cuentos de Fray Mocho, de José Sixto Álvarez (1943); Aleijadinho, de Antonio Francisco Lisboa (1944); Conquista de México. Carta de Hernán Cortés a Carlos V, con prólogo de Pedro Larralde (1944); Maravilla ¿qué será? (1944); Juan Moreira de Eduardo Gutiérrez, en versión teatral de Podestá (1944); Frank Brown de Dardo Cúneo (1944); Leyendas del

\footnotetext{
${ }^{10}$ La indicación de esta carta -así como las de las demás citadas en el presente artículo- remiten al epistolario conservado en la Fundación Luis Seoane de A Coruña (FLS), epistolario en proceso de digitalización y puesta a disposición pública en la página del Consello da Cultura Galega.

${ }^{11}$ En el número 10 de Correo Literario, del $1^{\circ}$ de abril de 1944 sobre el grabador mexicano José Guadalupe Posada, acerca del cual Nova había publicado una monografía en su colección Mar Dulce el año anterior, y sobre el pintor peruano Pancho Fierro, acerca del cual se publicaría un libro en la misma colección al año siguiente: "En fin, lo esencial en estos dos artistas americanos, como muy bien dice de Fierro, nuestro colaborador Antonio Berni, el brillante artista argentino, primer premio nacional de pintura este año, es su entrañable enraizamiento en el alma popular, que es la única que da tono seguro, timbre cierto al espíritu nacional, en cualquier parte donde sea oída. En ellos está la fuente de la picaresca, de la farsa, del drama, de la novela y de la poesía que quieran hondamente decirlo que de universal tiene América. Maravilloso material para el artista y el literato de gran vocación que quiera adentrarse en el alma continental, en la aventura de sus pueblos”.
} 
Federico Gerdhart. Temas y autores argentinos...

Tucumán de Alberto Franco (1944); Cuentos del fogón: excursión a los indios ranqueles de Lucio Mansilla (1944); Los caudillos del año XX, compilado por León Benarós (1944); Popol Vuh (1944); Rabinal Achi: drama danzado de los indios Quichés, editado por José Antonio Villacorta (1944); Mates burilados: arte vernacular peruano de José Sabogal (1945); Pancho Fierro (1945); Pequeña antología de cuentos brasileños, seleccionados por Marques Rebelo, traducidos por Raúl Navarro y comentados por Baudizzone (1946); Garibaldi en América de Newton Freitas (1946); y Fausto de Estanislao del Campo, con prólogo de Jorge Luis Borges (1946). ${ }^{12}$

$\mathrm{Al}$ igual que en Buen Aire, este repaso pone de relieve el enfoque de la colección en el pasado americano, dando lugar a material folklórico, tradicional y popular, que incluye aspectos distintivos de las culturas indígenas, de las coloniales de origen hispánico o portugués, y de las criollas. Este panorama, a su vez, se completa con algunos de los títulos incluidos en otras colecciones mucho menos extensas, como Nuestra América -Don Casmurro de Machado de Assis $(1943)^{13}$, y Recuerdos de provincia de Domingo Faustino Sarmiento (1943)-, la Biblioteca Americanista -Los aborígenes argentinos de Antonio Serrano (1947)- y Viajeros de las Américas -Noticias americanas de Antonio de Ulloa (1944), Viaje a las Indias del Mar Océano de Nicolás Federmann (1945) y Viaje y cautiverio entre los caníbales de Hans Staden, traducido del portugués por María E. Fernández (1945)-, dirigidas por Luis Aznar.

Según afirma Seoane en carta a la estudiosa Emilia de Zuleta, las colecciones americanas de Nova se habrían propuesto ser un complemento de las colecciones de temas y autores gallegos publicadas por la misma editorial, apoyadas todas ellas en una misma concepción de la cultura, explicación que el artista gallego hace válida también para las colecciones de Emecé referidas en el apartado anterior:

\footnotetext{
12 Sobre algunos de estos volúmenes dice Seoane en la citada entrevista: "Nosotros empezamos editando libros inverosímiles entonces, por ejemplo, la monografía, después en Mar Dulce, de Pancho Fierro, que nadie sabe aún hoy quién es [...] o a un acuarelista de la colonia en el Perú, realmente extraordinario, es decir, post-colonia ya, prácticamente de comienzo del diecinueve, este... Guamán Poma de Ayala, el primer dibujante que hubo en América después de la conquista [...] y que los dibujos no se conocían en Buenos Aires. [...] Y entonces hicimos una pequeña colección de esos dibujos... en Mar Dulce. Ahí se editaron también El Aleïadinho, un brasileño, se editaron los Mates burilados, otro libro del peruano, muy interesante, y así fueron editados muchos libros, libros americanos. Yo edité, yo hice la antología y este... de la sección de los grabados y además hice un pequeño prólogo para Guadalupe Posada, grabador mejicano" (2009: 167).

${ }^{13}$ Había sido anunciada como primera entrega de la colección Tierra Firme, la cual nunca se publicó tal vez por la coincidencia con el título de la famosa colección americanista que el Fondo de Cultura Económica sacó a la calle en 1944 .
} 
Federico Gerdhart. Temas y autores argentinos...

...nuestros deseos [eran], entonces, de incorporarnos al desarrollo cultural de Buenos Aires. Varela, Cuadrado y yo procedíamos, militando en partidos distintos, del autonomismo gallego y creíamos, seguimos creyendo, en las diferencias regionales creadas por herencias culturales e históricas distintas. Queríamos afirmar la situación cultural de cada uno de los países americanos y su aporte diferencial a la cultura universal. No conseguimos, seguramente, realizar nuestros propósitos [...] nuestras inquietudes que se prolongaron en las colecciones de libros, Buen Aire, que fundamos en Emecé dedicada al pasado argentino, y en Mar Dulce, más dedicada a la América de origen español y portugués, que fundamos en la Editorial Nova. (FLS, 21/11/1978)

No obstante la explicación de Seoane, la distribución en colecciones separadas, con diferentes diseños distintivos e incluso publicidad discriminada ${ }^{14}$ no parecería responder efectivamente a aquel deseo de Cuadrado, Varela y el propio Seoane de "incorporarse al desarrollo cultural de Buenos Aires”. Frente a esto, cabe destacar que una dinámica diferente en la relación entre los exiliados y el campo literario receptor puede observarse en otra de las colecciones de Nova, mencionada anteriormente. Se trata de Paloma, la continuación con título castellanizado, de Pomba.

En la colección Paloma, y bajo la dirección de Arturo Cuadrado, podría decirse que se produjo lo que Fernando Larraz denomina una "fusión transatlántica" (2011: 140), es decir, la coexistencia dentro de una misma colección de escritores rioplatenses y españoles exiliados. Entre los primeros pueden mencionarse a Ulyses Petit de Murat (Aprendizaje de la soledad, de 1943), Cayetano Córdova Iturburu (El viento en la bandera, de 1945), Alberto Girri (Playa sola, de 1946) y Vicente Barbieri (Anillo de sal, de 1946), y a las uruguayas Sarah Bollo (Antología lírica, de 1948) y Clara Silva (La cabellera oscura, de 1945); entre los segundos se encuentran Arturo Serrano Plaja (Versos de guerra y paz, de 1945), Jesús Cancio (Maretazos, de 1947) y el propio Arturo Cuadrado bajo el seudónimo de Venancio Viera (Los peces turbados, de 1945). Asimismo, el carácter diferencial de esta colección con respecto a las antes mencionadas reside en su carácter contemporáneo, es decir que los títulos no están orientados a rescatar, preservar o difundir un acervo cultural del pasado sino que consisten en la edición de autores que se desenvuelven en el campo literario local de la época. Esta línea, iniciada por Paloma, será retomada y ampliada en el siguiente proyecto editorial encarado por Seoane y Cuadrado, surgido al abrigo de Nova. ${ }^{15}$

\footnotetext{
${ }^{14}$ Tal como puede observarse en las páginas bibliográficas de, por ejemplo, Correo Literario.

15 Algunos especialistas como Pochat (1991: 170) y De Diego (2006: 100) afirman que Botella al Mar funcionó como una colección de Nova hasta 1952, cuando se independizó para establecerse como editorial. Sin embargo, en las ediciones de Botella al Mar puede observarse que Nova figura sólo como “concesionario exclusivo para la venta”.
} 


\section{Las Ediciones Botella al Mar}

El sello editorial Botella al Mar constituye el proyecto editorial se convertirá en el de más largo aliento entre los promovidos por Cuadrado y Seoane, comprendiendo más de ciento cincuenta títulos. Atendiendo al catálogo de sus primeros años, puede observarse la presencia destacada de autores de la llamada "generación del “40" de la poesía argentina, tales los casos de Vicente Barbieri, con su Desenlace de Endimión (1951), Horacio Jorge Becco, con sus Campoemas (1952), Eduardo Jonquieres, con Los vestigios (1952), y Alberto Girri, con cinco títulos: Coronación de la espera (1947), Trece poemas (1949), El tiempo que destruye (1950), Escándalo y soledades (1952) y Misántropos (1953). ${ }^{16}$ Afirma Seoane acerca de sus emprendimientos editoriales junto a Arturo Cuadrado por esos años, en "Dos imprentas y mis tapas", que sacaban a la luz "sin afanes comerciales, los libros más extraños y desconocidos, esos que nadie arrebata en las librerías y que siguen silenciosos su destino a través del tiempo, pero que constituyen el estilo de una época, la flor de la historia cultural de un pueblo" (1953: s/p). Casi dos décadas más tarde, entrevistado en 1972 recuerda que

Botella al Mar tenía la pretensión de ser una colección de poesía para gente joven, para gente joven que no tenía editorial [...] Incluso muchos de los grandes poetas argentinos actuales nacieron ahí, uno de los primeros que editamos nosotros fue Alberto Girri, Alejandra Pizarnik ${ }^{17}$, que acaba de fallecer, la editamos nosotros primero que nadie, verdad, muchos libros se editaron en Botella al Mar en un momento importante. (Seoane, 2009: 167)

A su vez, y de modo más esperable, en sus primeros años el sello incluye también obras de autores españoles exiliados, como los mismos editores gallegos y otros cercanos a ellos: cuatro de Seoane -Tres hojas de ruda y un ajo verde o las narraciones de un vagabundo (1948), Veinte dibujos (1950), Paradojas de la torre de marfil y Testimonios de vista. 33 retratos en dibujos (1952)-, tres de Cuadrado -Heredia (1948), Dibujos de Seoane (1950) y Soledad imposible (1952)-, tres de Lorenzo Varela -Seoane (1948), Lonxe (1954) y Falcini (1954)-, uno de Manuel Colmeiro -Carpeta de pintor (1947)- y uno de Arturo Serrano Plaja -Phokas el americano. Poemas en prosa (1948)-.

\footnotetext{
${ }^{16}$ A los citados se suman otros títulos como: Costumbres errantes o la redondez de la tierra, de Enrique Molina (1951); La ley de gravedad, de Carlos Latorre (1952); Negada permanencia y La siesta y la naranja, de Juan José Hernández (1952); y La otra cara de la luna, de Juan José Ceselli (1953).

${ }^{17}$ La tierra más ajena (1955).
} 
Federico Gerdhart. Temas y autores argentinos...

Por último, también desde sus comienzos, Botella al Mar dio cabida en su catálogo a otros autores latinoamericanos como los brasileños Newton Freitas (Jaburuna. Cuentos y relatos, de 1949), Carlos Drummond de Andrade (Dos poemas, de 1953) y Manuel Kantor (Autocaricatura del caricaturista adolescente 1926-1929, de 1956); el argentino nacionalizado brasileño Carybé, seudónimo de Héctor Julio Páride Bernabó (Atjuss, de 1948); el peruano Sebastián Salazar Bondy (Los ojos del pródigo, de 1951); la chilena Margarita Aguirre (Cuadernos de una muchacha muda, de 1951); el guatemalteco Miguel Ángel Asturias (Ejercicios poéticos en forma de soneto sobre temas de Horacio, de 1951); y la uruguaya Clara Silva (La sobreviviente, de 1951).

Esta pretensión de integración e incidencia en el campo literario local, visible en diferente medida en las editoriales y colecciones antes citadas podría leerse también en otras empresas que eran simultáneamente desarrolladas por el mismo grupo de exiliados en la prensa periódica porteña, y que constituyeron una parte fundamental de su entramado editorial.

\section{Las revistas: De Mar a Mar y Correo Literario}

El crecimiento de la industria editorial, al que se hizo referencia al principio del presente trabajo, no se circunscribió al mercado del libro sino que tuvo también su correspondencia en las publicaciones periódicas y, específicamente, en las revistas (Rivera, 1998: 96-103), apoyada en las mismas circunstancias favorables, incluyendo los efectos de la Guerra Civil española (Eujanián, 1999: 30). También en este ámbito de la edición, el grupo de exiliados gallegos desarrolló una tarea destacada, por un lado, como colaboradores -aunque, en algunos casos, incluso desempeñaron otras funciones- en periódicos como La Prensa, La Nación, Noticias Gráficas y Crítica, y revistas como Sur, Boletín Literario o El Hogar (Zuleta, 1999: 73-93; Pérez Rodríguez, 2004: 127). Pero, al mismo tiempo, la prensa periódica se convirtió en un campo propicio para el desarrollo de proyectos editoriales propios, y estrechamente relacionados con el papel desempeñado en el campo de la edición de libros. De modo similar a lo que sucedía por entonces en México, con la publicación de revistas promovidas por los refugiados españoles como España Peregrina, Romance o Las Españas, ${ }^{18}$ el grupo de exiliados gallegos llevó adelante en Buenos Aires la edición de sus propias revistas culturales, entre las que se cuentan De Mara

\footnotetext{
${ }^{18}$ Sobre las revistas culturales del exilio español en México, v. el detenido estudio de Francisco Caudet (2007). Un panorama más breve de las revistas literarias del exilio español, con especial foco en las editadas en Francia, México y la Argentina, puede encontrarse en Molina (1990: 269-290).
} 
Federico Gerdhart. Temas y autores argentinos...

Mary Correo Literario.

En diciembre de 1942 apareció el primer número de De Mar a Mar, título que en ésta y sus posteriores entregas fue acompañado por la indicación "Revista literaria mensual". A la cabeza del grupo fundador se encontraban, como secretarios, dos exiliados de la Guerra Civil española: Lorenzo Varela, quien venía de participar en México de las revistas Taller y Romance, y Arturo Serrano-Plaja, con pasado en La Gaceta Literaria, El Sol y Hora de España en la Península, y luego también en Romance (Caudet, 2007, p. 181-183). A Varela y Serrano-Plaja se sumaban, dentro del grupo fundador y como colaboradores asiduos, Arturo Cuadrado y Luis Seoane, así como también Manuel Colmeiro, ilustrador de libros para Emecé, y Rafael Dieste, director del departamento editorial de Atlántida. Los ejemplares de la revista se imprimían en los talleres de la antes mencionada Imprenta López.

Tras el cese de la revista De Mar a Mar, cuya última entrega fue el número 7, de junio de 1943, el 15 de noviembre de ese mismo año comienza su andadura Correo Literario, "Periódico quincenal” que, a partir del número 37 tendrá frecuencia mensual hasta el número 40, del $1^{\circ}$ de septiembre de 1945 , cuando deja de editarse. ${ }^{19}$ El grupo directivo de la nueva publicación estaba compuesto íntegramente por colaboradores de De Mar a Mar: los directores eran Arturo Cuadrado, Luis Seoane y Lorenzo Varela, y el secretario Javier Farías..$^{20}$ Además de contar con los mismos promotores, ambas revistas coinciden en prestar especial atención al desarrollo de la industria cultural y, más específicamente, del mercado editorial tanto en la Argentina como, en

${ }^{19}$ Con respecto a las causas del cierre de Correo Literario, existen diferentes hipótesis. Por un lado, Xesús Alonso Montero (1994: 9) sostiene que el avance de la Segunda Guerra Mundial habría alimentado las expectativas depositadas en la destitución de Franco y el retorno de los exiliados, incluido el grupo que llevaba adelante el quincenario. Por otro lado, más recientemente, Beatriz Sarlo sugiere, como causa del cese, una persecución política por parte de "la Argentina peronista, aquel otro país que sólo muy eventualmente, sólo si se perseguía a alguna publicación o se la cerraba, como al parecer sucedió con Correo Literario, se tocaba con el mundo intelectual y artístico en el que se movía Seoane" (2012: 39; cursivas de la autora). Extendiendo la perspectiva en el tiempo, en ambos sentidos, Emilia de Zuleta se refiere al derrotero del proyecto iniciado con De Mar a Mar y continuado por Correo Literario, señalando que "este programa habría de naufragar por razones de orden internacional y local. Primero, las crecientes disensiones entre los "pueblos libres" y, más particularmente, el repliegue de los mismos frente al agresivo imperialismo soviético, cuya primera consecuencia fue, junto con otros factores como la habilidad política de Franco, la atribución de un nuevo papel a España en el orden internacional. En el orden local, ya hemos señalado que el surgimiento del peronismo, en 1945, produjo un cambio radical en las condiciones de vida del intelectual de Buenos Aires y, lo que fue no menos decisivo, un nuevo reagrupamiento de tendencias y figuras, tanto en lo ideológico como en lo intelectual" (1983: 160-161).

${ }^{20}$ No obstante, no se trataría de un relevo de la publicación anterior, ya que, aunque como se ha dicho la publicación había cesado en junio de 1943, ya avanzado el año 1944 seguía apareciendo en las páginas de Correo Literario la publicidad que invitaba a los lectores a suscribirse a De Mar a Mar. Esto además podría plantear una posible explicación sobre las causas del cierre de la revista. 
menor medida, en los demás países latinoamericanos.

La sección bibliográfica de De Mar a Mar se publicaba bajo el título "Libros” y ocupaba un espacio considerable: entre seis y nueve páginas de las aproximadamente cincuenta que tenía cada número. De acuerdo con el objetivo de difundir la obra de los exiliados entre otros desterrados e integrarse en la cultura argentina, dicha sección bibliográfica de De Mar a Marincluida en la más amplia "Mirador", que albergaba además novedades de cine, teatro y artes plásticas- otorgó un lugar preponderante a los libros editados en Buenos Aires por los sellos a los que se hallaba ligado el grupo fundador, fundamentalmente, Nova, pero también Losada, Atlántida, Poseidón y Sudamericana. Como contraparte, las citadas editoriales aportaban al sostén económico de la revista mediante la publicidad, generalmente, a página completa, que ocupaba alrededor de cinco páginas en cada número, en folios agregados al principio y al final del mismo. $^{21}$

En consecuencia, esta “crítica de soutien” (Zuleta, 1999: 58) se aplicó también a los libros editados dentro de las colecciones de tema americano de Nova. Es así que, por ejemplo, en el número 4, de marzo de 1943, el brasileño Newton Freitas firma una reseña de los dos libros que inauguran la colección Mar Dulce -en la que también verán la luz volúmenes a su cargo-, Guaman Poma y La calavera y otros grabados de Guadalupe Posada, elogio que se abre recordando asimismo el precedente de Buen Aire en Emecé:

La mera elección de estos dos interesantes tomos para iniciar una colección, bastaría por sí misma para garantizar su criterio artístico y su rectitud literaria. No obstante, es preciso considerar que esta Colección está dirigida por Luis M. Baudizzone y por Luis Seoane, que junto a Arturo Cuadrado fundaron, y dirigieron hasta el número 15, la Colección Buen Aire. En aquella Colección, hoy tan conocida, quedó demostrada la capacidad de sus directores, tanto en la selección de los textos como en el cuidado gráfico y en la confección artística. Era, pues, de esperar que Mar Dulce se presentase como se presentó, dadas las credenciales de quien la dirige. Y basta hojear estos dos tomos recientemente aparecidos para constatar esta verdad. (Año II, $\mathrm{n}^{\circ} 4$, p. 41)

También Correo Literario guardó, dentro de la atención prestada a la actividad cultural desarrollada en los países de la región -en especial, en la ciudad de Buenos Aires-, un espacio destacado para el panorama editorial argentino. La crítica ocupaba la sección "Libros y autores", que incluía: una nota bibliográfica extensa, cercana al ensayo; de seis a doce reseñas, en las que se prestó especial atención a las ediciones realizadas por los españoles en Buenos Aires; y noticias breves sobre libros recientemente publicados o de próxima aparición, acompañadas en

21 Para un análisis parcial de las relaciones entre crítica literaria y mercado editorial en las páginas de De Mar a Mar, v. Gerhardt (2013). 
ocasiones de novedades relacionadas con la actividad, como aperturas de librerías o instalaciones editoriales. A todo esto se sumó, a partir del número 31, una sección titulada "El mercado de los libros", de irregular frecuencia, firmada con seudónimos y dedicada a registrar el curso de la actividad y a explorar las causas de las alzas y las bajas.

Al igual que sucedía en su predecesora, en Correo Literario las páginas bibliográficas de dialogaban $^{22}$ con la publicidad editorial, en la medida en que los libros objeto de la crítica pertenecían muchas veces a los sellos que anunciaban en la misma revista: Nova, Poseidón, Losada, El Ateneo y Sudamericana, a las que se sumaba la Imprenta López. ${ }^{23}$ A propósito de esto, el 15 de diciembre de 1943, ya en uno de los primeros números, una nota de la redacción explica, bajo el título "Premáticas y desahogos", la incidencia de la prensa cultural en los circuitos de edición, circulación y difusión de los libros:

El estruendoso éxito de una obra depende: un diez por ciento de la editorial, un veinte por ciento de la publicidad, un veinte por ciento de la crítica literaria de la gran prensa seria, un cinco por ciento de las revistas literarias de minoría, un treinta por ciento del distribuidor y de los libreros, un cinco por ciento de la crítica honesta. El restante diez por ciento depende, a partes iguales, del acierto del título y del valor verdadero del libro. (Año $\mathrm{I}_{\mathrm{n}}{ }^{\circ} 3$, p. 2)

Es así que, además de contar con anuncios publicitarios a lo largo de cada número, en las secciones bibliográficas de Correo Literario encontraron su lugar los libros de las colecciones de temas y/o autores latinoamericanos de la editorial Nova ${ }^{24}$, tales los casos de: Amazonia. Leyendas Ñangatú de Newton Freitas (Año I, n 3, p. 6), Cuentos del fogón: excursión a los indios ranqueles de Lucio Mansilla (Año II, $\mathrm{n}^{\circ}$ 7, p. 6), Popol Vuh y Juan Moreira de Podestá (Año II, n ${ }^{\circ}$ 8, pp. 6-7), Guamán Poma y La calavera y otros grabados de Guadalupe Posada (Año II, $\mathrm{n}^{\circ}$ 9, p. 7), Aleïadinho de Antonio Francisco Lisboa (Año II, n ${ }^{\circ}$ 18, p. 6), Los

\footnotetext{
${ }^{22}$ El tono de este diálogo parece haber despertado algunas suspicacias en los lectores del momento, a juzgar por la nota en la que, bajo el título "Premáticas y desahogos", la redacción acusa recibo de sus reclamos: "Si nos gustara el escándalo podríamos hacer en Correo Literario una sección de verdadero éxito, publicando con pelos y señales las quejas que verbalmente llegan por nuestra 'falta de agresividad' en los comentarios de libros" (Año I, n ${ }^{\circ}$ 9, 15 de marzo de 1944, p. 2 ).

${ }^{23}$ Los vínculos entre Correo Literario y otros agentes del campo editorial de la época se vuelven aún más explícitos en el balance del primer año de publicación. La "Carta abierta" del número 24, del $1 .^{\circ}$ de noviembre de 1944 , destaca: "Las casas editoras, imprentas y librerías argentinas prestaron también su ayuda al empeño de sostener un periódico íntegramente literario. Para que quede constancia de nuestro agradecimiento, citaremos especialmente algunas firmas: Imprenta López, la Editorial Poseidón, la Editorial Losada, la Editorial Nova, la librería El Ateneo, que nos apoyaron lealmente desde nuestra aparición" (Año II, $\mathrm{n}^{\circ} 24$, p. 2 ).

${ }^{24}$ En ocasiones, la promoción de los libros de la colección Mar Dulce también presentaba otras formas menos “directas" en las páginas de la publicación (v. nota 11).
} 
caudillos del año XX de León Benarós (Año II, $\mathrm{n}^{\circ}$ 26, p. 6), Conquista de México. Carta de Hernán Cortés a Carlos V (Año III, n²9, p. 7), Viaje a las Indias del Mar Océano de Nicolás Federmann (Año III, n³6, p. 6) y Viaje y cautiverio entre los caníbales de Hans Staden (Año III, $\mathrm{n}^{\circ}$ 40, p. 6), títulos todos ellos de Mar Dulce, a excepción de los últimos dos, pertenecientes a la colección Viajeros de las Américas, según se ha señalado previamente.

Pero, al mismo tiempo, además de este vínculo más evidente y explícito, interesa otro aspecto de las citadas publicaciones periódicas que podría leerse en relación con las colecciones de temas y autores latinoamericanos antes referidas y tiene que ver con la intención de los exiliados de integrarse e integrar sus proyectos editoriales en el campo cultural que los acogió.

En su breve texto de presentación, incluido en el número inicial, el grupo fundador de $D e$ Mar a Mar compuesto, como se ha dicho, fundamentalmente por exiliados gallegos, manifiesta la voluntad de integrar la publicación en el campo literario local, pretensión que a lo largo de los siguientes seis números se irá realizando por medio de la inclusión de una creciente nómina de colaboradores compuesta no sólo por exiliados sino también por los nombres de escritores y artistas argentinos, y, en menor medida, uruguayos y brasileños. Concluye la presentación de la revista, diciendo: "De Mar a Mar se inicia al calor fraternal de unos cuantos amigos, europeos y americanos, unos en Buenos Aires, otros dispersos por el continente" (Año I, n 1, p. 6).

En este sentido, una característica interesante, señalada ya tempranamente por la crítica (Zuleta, 1983: 162), es la creciente nómina de colaboradores. Junto a los nombres que componen el núcleo inicial de la revista se agrega una serie de firmas, en constante aumento, que se incluye en cada entrega. La nómina del primer número está compuesta por los siguientes artistas y escritores: Luis Seoane, Arturo Cuadrado, Manuel Colmeiro, José Otero Espasandín, Rafael Alberti, Francisco Ayala, Guillermo de Torre, Ramón Pontones y; los argentinos Enrique Anderson Imbert, Horacio Butler, Eduardo Mallea, Ricardo Molinari, Eduardo Sacriste, el ítaliano Attilio Rossi (autor de la viñeta de tapa del primer número) y el brasileño Newton Freitas. La lista se cierra con un etcétera que se irá completando en los números siguientes. En el segundo se agregan: el uruguayo Juvenal Ortiz Saralegui, y el español Antonio Sánchez Barbudo; en el tercero, los españoles Urruchúa y Bernardo Clariana, y el argentino José Luis Romero; en el cuarto, el francés-uruguayo Jules Supervielle; en el quinto los españoles Ricardo Baeza, Antonio Baltar, Alejandro Casona y Javier Farías, y el uruguayo-español Enrique Dieste; en el sexto, los argentinos Julio Caillet Bois y Ricardo Donghi Halperín, el español Ramón Gaya y el mexicano Octavio Paz; y en el séptimo y último, el español Francisco Aparicio, el argentino Luis Baudizzone y el uruguayo Cipriano Vitureira. 
La composición de esta nómina, aumentada número a número, podría considerarse como, en palabras de Lorenzo Varela, un "intento claro de integración con los intelectuales iberoamericanos" (2001: 166) ${ }^{25}$, incorporando firmas que gozaban de cierto prestigio en el campo cultural local o estaban buscando posicionarse dentro del mismo. ${ }^{26}$ Aunque podría presentar ciertos matices diferentes ${ }^{27}$, Correo Literario retoma en este aspecto particular el proyecto interrumpido de De Mar a Mar. ${ }^{28}$

El número inaugural de Correo Literario, publicado el 15 de noviembre de 1943, incluye una declaración de principios que sigue los lineamientos planteados en la presentación de la revista previa. Con el título de "Al lector", la publicación presenta de modo resumido sus intenciones:

Correo Literario aspira a ser un periódico de mayoría, al servicio de la cultura hispanoamericana, difundiendo sus valores en cuanto esté al alcance de sus posibilidades.

Sus páginas irán reflejando las inquietudes más candentes a lo largo de América, tanto las propias y características del continente, como las de los diferentes grupos de desterrados acogidos a la generosidad de estas tierras. [...] Estamos convencidos de que, para un propósito así, hemos de encontrar la más amplia y fervorosa colaboración. Con ella contamos para realizar nuestra idea primordial: Dotar al movimiento cultural de habla española, del instrumento de difusión que haga posible un constante intercambio a través de un correo diligente y leal. (Año $\mathrm{I}_{1} \mathrm{n}^{\circ} 1, \mathrm{p} .1$ )

${ }^{25}$ A propósito de esto, es oportuno señalar -aunque no cabe aquí desarrollar un análisis de la cuestión-, que los diferentes agentes involucrados en estos proyectos utilizan de forma prácticamente indistinta los adjetivos "latinoamericano" e "iberoamericano" cuando se incluye al Brasil, e "hispanoamericano" cuando se lo excluye, tal como se observa en algunos de los testimonios recogidos en este trabajo.

${ }^{26}$ Acerca de los vínculos establecidos entre De Mar a Mar y otras zonas del campo literario local, cabe destacar que la revista Sur publicó una breve pero elogiosa nota sobre la aparición de De Mar a Mar, a la que saluda como una "nueva revista que agrupa a conocidos escritores, muchos de ellos expatriados" y de la que destaca: "es elogiable la presentación material de la revista”. Lo curioso es que la noticia ve la luz en la revista de Victoria Ocampo el $1^{\circ} \mathrm{de}$ julio de 1943, es decir, un mes después de la fecha de la última entrega de De Mar a Mar (Sur, Año XII, n ${ }^{\circ}$ 105, p. 114). Esto, sin embargo, podría explicarse considerando el desfasaje, señalado por Dolinko (2010) entre la fecha que figuraba al frente de cada número, y la fecha real de publicación.

${ }^{27}$ Algunos de estos matices, en relación con las artes plásticas son abordados en: Dolinko (2008 y 2010).

${ }^{28}$ Mucho menos demorada y aún más elogiosa es la noticia que en la misma revista Sur, el $1^{\circ}$ de diciembre de 1943 , da cuenta del comienzo de Correo Literario. Con su característica francofilia, la noticia comienza afirmando: "Siempre se sintió la necesidad, en los países de habla española, de un periódico semejante a Les nouvelles littéraires. Correo Literario tiene el propósito de llenar ese vacío; su presentación y su material son excelentes" (Sur, Año XII, $n^{\circ} 110$, p. 113). 
Estas líneas ponen de relieve la orientación americanista de la publicación, en consonancia con la voluntad de los exiliados españoles de integrarla al campo cultural del país y del continente receptores. Dicha orientación se hace patente no sólo en la antes mencionada atención a la actividad cultural de las naciones latinoamericanas -sobre todo, aunque no exclusivamente, de la Argentina-, sino además en la lista de autores que aportan sus escritos a la publicación.

Entre los colaboradores de Correo Literario pueden mencionarse, por un lado, exiliados españoles como Rafael Dieste, Francisco Ayala, Clemente Cimorra, Arturo Serrano Plaja, Rafael Alberti y María Teresa León, además de los integrantes del grupo directivo. Por otro lado, la publicación recibe el importante aporte de escritores argentinos entre los que se destacan, por su asiduidad en la firma de reseñas, Pedro Larralde y Alberto Girri, éste último también autor de piezas poéticas y ensayísticas en varios números. Otras firmas argentinas en las páginas de Correo Literario son Cayetano Córdova Iturburu y Ulises Petit de Murat, en forma recurrente, y, esporádicamente o en una sola oportunidad, Nicolás Olivari, Homero Manzi, Leónidas Barletta, Elías Castelnuovo, Eduardo Mallea, María Rosa Oliver, León Benarós, Juan L. Ortiz, Juan José Manauta, Vicente Barbieri, Enrique Molina, Horacio J. Becco, Ernesto Sábato y Julio Cortázar. ${ }^{29}$

En relación con los demás países, el acento latinoamericanista de la publicación reside sobre todo en sus vínculos con Uruguay y con Brasil, aunque ocasionalmente recibe también las contribuciones de otros notables literatos como, por ejemplo, el mexicano Octavio Paz, la chilena Gabriela Mistral y el ecuatoriano Jorge Icaza. La relación con Uruguay abarcó tanto las noticias acerca de la marcha de las letras y las artes en ese país, como la colaboración de varios de sus escritores, entre los que se cuentan: Juvenal Ortiz Saralegui -autor habitual de las sección "Libros y autores"-, Juana de Ibarbourou, Carlos Sabat Ercasty, Enrique Amorin, Alberto Zum Felde, Sara de Ibáñez y Esther de Cáceres. En el caso de Brasil, la figura más destacada fue la de Newton Freitas, quien estaba íntimamente vinculado con Varela y con Seoane. ${ }^{30}$ Freitas contaba con una sección fija titulada "Colaboración en portugués" que se ubicaba en la página siete de cada número, dedicada a temas literarios y culturales. Además, Correo Literario recibió colaboraciones de otros autores como tales los casos de Carlos Drummond de Andrade, Manuel

\footnotetext{
${ }^{29}$ En la entrega del 15 de agosto de 1944 se publica su relato "Bruja” (Año II, n ${ }^{\circ}$ 19, p. 3).

${ }^{30}$ Sobre la relación de Freitas con Varela y Seoane, y su incidencia en las empresas editoriales de los exiliados gallegos, v. Pérez Rodríguez (2009b) y Navas Sánchez-Élez (2009). En este sentido, la edición de autores brasileños en la Argentina seguía dependiendo de las relaciones personales como en años anteriores (Sorá, 2010: $201 \mathrm{ss})$.
} 
Kantor y Vinicius de Moraes, y de Mário de Andrade, escritor a cuya figura, con ocasión de su muerte, es dedicado un homenaje en el número 36 del 15 de mayo de $1945 .{ }^{31}$

Por último, cabe destacar que, a partir de esta revista surgió una efímera editorial, también dirigida por Cuadrado y Seoane, cuyos únicos dos títulos, uno efectivamente publicado y otro anunciado pero que nunca vio la luz, se deben a una escritora uruguaya y a un joven escritor argentino, respectivamente. En diciembre de 1945, meses después de la aparición del último número de Correo Literario, se imprimió el libro Antología (1929-1945) de Esther de Cáceres, que sería el único efectivamente publicado por el sello Ediciones Correo Literario de que se tenga noticia, aunque previamente, en el número 29 del 15 de enero de 1945, una publicidad anuncia, en las páginas mismas del quincenario, la aparición de Llanto meditado de Alberto Girri como "el primer libro de poesía con el cual inicia la serie de publicaciones Correo Literario". El volumen de Esther de Cáceres estaba ilustrado por Luis Seoane y prologado por un poema de Rafael Dieste, y su distribución estaba a cargo de la Editorial Nova.

\section{De las revistas a las colecciones: consideraciones finales}

Las líneas previas recorren los proyectos editoriales fundados y promovidos por un grupo de exiliados de ascendencia gallega, nucleados en torno a las figuras de Luis Seoane, Arturo Cuadrado y Lorenzo Varela, en el contexto de la llamada "época de oro" de la industria editorial argentina -fundamentalmente, a lo largo de la década del 40-, enfocando la lectura en los lugares ocupados por los libros de temas y autores argentinos y, más ampliamente, latinoamericanos. En el caso de la editorial Emecé y en el periodo en el que los mencionados exiliados tuvieron a su cargo funciones directivas, su catálogo ubica, por un lado, las colecciones galleguistas Hórreo y Dorna, y, por otro, la colección Buen Aire, destinada al pasado latinoamericano, en la que se destaca la presencia de material tradicional, folklórico y popular, además de los escritos de conquistadores, viajeros y próceres. En la siguiente empresa editorial, Nova, la colección Mar Dulce retoma los lineamientos generales de Buen Aire, y se vuelca fundamentalmente al pasado, remontándose a tiempos precolombinos y atendiendo a aspectos distintivos de las culturas indígenas, de las coloniales de origen hispánico o portugués, y de las criollas.

No obstante, en el seno de la misma editorial se desarrolla una colección que, en sus inicios, también se plantea como destinada a la cultura gallega, Pomba, pero que más tarde

\footnotetext{
31 La relación de Mário de Andrade con la Argentina a comienzos de los años 40, como contexto amplio de esta conmemoración es analizado en: Artundo (2004).
} 
castellaniza su nombre, Paloma, y comienza a incorporar, junto a los españoles, a autores contemporáneos argentinos y uruguayos, conformando un catálogo que daría cuenta de una paulatina integración en el campo literario local. Esta línea, iniciada en la colección Paloma, será desarrollada en el proyecto editorial llevado adelante por Cuadrado y Seoane, a partir de 1947, casi coincidiendo con su apartamiento de Nova. Desde su lanzamiento, hacia fines de la década del '40 y principios de la del ‘ 50 , Botella al Mar fue conformando un catálogo de obras contemporáneas, con preponderancia de la poesía, donde se fusiona los libros de exiliados españoles con los títulos de los argentinos, con menor aunque también importante presencia de otros autores latinoamericanos, fundamentalmente brasileños. Esta operación tendiente a estrechar las relaciones con el campo cultural receptor, toma forma también en otros proyectos editoriales del mismo grupo de exiliados en la prensa periódica porteña de principios de los años cuarenta: De Mar a Mar y Correo Literario.

En ambas publicaciones culturales, desde el principio de cada una y en forma sostenida hasta los respectivos cierres, la nómina de colaboradores estará compuesta no sólo por intelectuales y artistas españoles exiliados sino también por sus pares argentinos y, aunque en menor medida, de otros países latinoamericanos. En este sentido, De Mar a Mar y Correo Literario presentan en sus páginas una fusión similar -incluso con muchas firmas en común- a la iniciada con la colección Paloma y continuada por Botella al Mar, aunque en el caso de las citadas revistas esta característica es observable más tempranamente, lo que podría explicarse considerando que las revistas constituyen un modo de intervención cultural más inmediato y atado a la coyuntura, si se lo compara con la edición de libros.

En su ya clásico estudio sobre "Intelectuales y revistas", Beatriz Sarlo afirma que "los índices de las revistas (como los catálogos de una editorial) son testimonios” (1990: 10). En el caso de las colecciones y revistas abordadas, unos y otros serían testimonios de la voluntad de los exiliados de la Guerra Civil española de integrarse en el campo cultural de la sociedad que les dio acogida cuando Europa era asolada por los fascismos. 
Federico Gerdhart. Temas y autores argentinos...

\section{Bibliografía}

Alonso Montero, Xesús (1994). "Cincuentenario de Correo Literario (Buenos Aires, 1943-1945)". Alonso Montero, Xesús (ed.) Correo Literario [edición facsimilar]. A Coruña: Ediciós do Castro: 7-10.

Artundo, Patricia (2004). Mário de Andrade e a Argentina. Um país e sua produção cultural como espaço de reflexão. São Paulo: Edusp.

Costa, Eugenia (2014). "Rescate de 'Botella al Mar'. Luis Seoane y el arte de editar" [en prensa]. Gerhardt, Federico (dir.) Memoria del III Congreso Internacional de Literatura y Cultura Españolas Contemporáneas. La Plata: FaHCE-Universidad Nacional de La Plata.

De Diego, José Luis (dir.) (2006). Editores y políticas editoriales en Argentina, 1880-2000. Buenos Aires: Fondo de Cultura Económica.

Devoto, Fernando (2012). "Cultura y política entre dos mundos: el exilio gallego en la Argentina, los debates intelectuales y las tramas de sociabilidad (1936-1963)”. Devoto, Fernando y Villares, Ramón (eds.) Luis Seoane entre Galicia y la Argentina. Buenos Aires: Biblos: 165-198.

Dolinko, Silvia (2008). "El rescate de una cultura universal. Discursos programáticos y selecciones plásticas en Correo Literario". Artundo, Patricia (dir.) Arte en revistas. Publicaciones culturales en la Argentina 1900-1950. Rosario: Beatriz Viterbo: 131-165.

Dolinko, Silvia. "Guerra, exilio e imágenes transatlánticas. Un análisis de la revista De mar a mar" Ciberletras-Revista de crítica literaria y de cultura - Journal of literary criticism and culture (2010).

Eujanián, Alejandro (1990). Historia de revistas argentinas 1900/1950. La conquista del público. Buenos Aires: Asociación Argentina de Editores de Revistas.

Fernández Santiago, Marcelino (2001). “Asociacionismo gallego en Buenos Aires (1936-1960)”. Seijas, Xosé Núñez (ed.) La Galicia Austral. La inmigración gallega en la Argentina. Buenos Aires: Biblos: 181-201.

Gerhardt, Federico (2013). "Entre la prensa y el libro, entre España y la Argentina. Crítica literaria y mercado editorial en la revista De Mar a Mar”. Astutti, Adriana, Garbatzky, Irina y Gasparri, Javier (coords.) Actas del III Congreso Internacional Cuestiones Críticas. Rosario: Facultad de Humanidades y Artes, Universidad Nacional de Rosario. 
Federico Gerdhart. Temas y autores argentinos...

Gerhardt, Federico. "Asociacionismo gallego y mercado del libro en la Buenos Aires del medio siglo: dos proyectos editoriales de Luis Seoane”. Madrygal. Revista de Estudios Gallegos 18 (2015): 457-467.

González Ledo, José (2008). La peña gallega del Tortoni. Buenos Aires: Alborada.

Larraz, Fernando (2010). Una historia transatlántica del libro. Relaciones editoriales entre España y América Latina (1936-1950). Gijón: Trea.

Larraz, Fernando (2011). "Los exiliados y las colecciones editoriales en Argentina (1938-1954)". Pagni, Andrea (ed.) El exilio republicano español en México y Argentina. Historia cultural, instituciones literarias, medios. Madrid-Frankfurt: IberoamericanaVervuert-Bonilla Artigas Editores: 129-144.

León, María Teresa. “Una editorial y su elogio”, España Republicana 21 de febrero (1942): 12.

Navas Sánchez-Élez, María Victoria (2009). "Relaçoes entre escritores gallegos e brasileiros no exilio espanhol: o testemunho de Lorenzo Varela e Newton Freitas". Rodríguez González, Olivia y Mariño Sánchez, Laura (coords.) Novas achegas ao estudo da cultura galega enfoques literarios e socio-históricos. A Coruña: Universidade da Coruña: 357-382.

Pérez Rodríguez, María Antonia (2004). "Luis Seoane e o 'Grupo Tortoni’ dentro do exilio galego en Bos Aires: 1937-1953”. AAVV. Xornadas sobre Luis Seoane. A Coruña: Xunta de Galicia: 125-140.

Pérez Rodríguez, María Antonia. "As editoriais no exilio arxentino/Las editoriales en el exilio argentino". Galegos=Gallegos 7 (2009a): 110-118.

Pérez Rodríguez, María Antonia (2009b). "Autores brasileiros en empresas editoriais dos exiliados galegos en Bos Aires: Emece, Nova, Botella al mar”. Rodríguez González, Olivia y Mariño Sánchez, Laura (coords.) Novas achegas ao estudo da cultura galega enfoques literarios e socio-históricos. A Coruña: Universidade da Coruña: 349-356.

Molina, César Antonio (1990). Medio siglo de prensa literaria española (1900-1950). Madrid: Endymion.

Pérez Rodríguez, María Antonia (2007). "O labor de Luis Seoane na prensa". Aneiros Díaz, Rosa et al. (eds.). Xornalistas con opinión. 20 biografías. Vigo: Consello da Cultura Galega-Editorial Galaxia: 323-338. 
Federico Gerdhart. Temas y autores argentinos...

Pérez Rodríguez, María Antonia (2013). "Nova 1942-1947: una editorial de exiliados gallegos en Argentina”. Santana, Adalberto (coord.) Setenta años de Cuadernos Americanos. México: Universidad Autónoma de México: 119-134.

Pochat, María Teresa (1991). “Editores y editoriales”. Sánchez-Albornoz, Nicolás (comp.) El destierro español en América. Un trasvase cultural. Madrid: Siruela-Sociedad Estatal Quinto Centenario-Instituto de Cooperación Iberoamericano: 163-176.

Rivera, Jorge (1998). El escritor y la industria cultural. Buenos Aires: Atuel.

Rodino Lalín, Hugo. “As editoriais galegas en Bós Aires”. Revista do Comisión Galega do Quinto Centenario 1 (1989): 49-71.

Rodino Lalín, Hugo (1991). “Asociacionismo gallego en Buenos Aires”. Clementi, Hebe (ed.) Inmigración española en la Argentina (Seminario 1990). Buenos Aires: Oficina Cultural de la Embajada de España: 289-314.

Sarlo, Beatriz. "Intelectuales y revistas: razones de una práctica”. Cahiers du CRICCAL 9/10 (1992): 9-16.

Sarlo, Beatriz (2012). “Las Argentinas de Seoane”. Devoto, Fernando y Villares, Ramón (eds.). Luis Seoane entre Galicia y la Argentina. Buenos Aires: Biblos: 29-46.

Schwarzstein, Dora (2001). Entre Franco y Perón. Memoria e identidad del exilio republicano español en Argentina. Barcelona: Crítica.

Seoane, Luis (1953). Libro de tapas. Buenos Aires: Botella al Mar.

Seoane, Luis. "Unha vida contada na radio. Luis Seoane dialoga con Vicky Linares é Cordova Iturburu”. Galegos=Gallegos 7 (2009): 161-180.

Sorá, Gustavo (2010). Brasilianas. José Olympio e a gênese do mercado editorial brasileiro. São Paulo: Edusp / ComArte.

Varela, Lorenzo (2001). "De Mar a Mar". Varela, Lorenzo. Ensayos, conferencias y otros escritos. II. A Coruña: Ediciós do Castro, Biblioteca del Exilio: 165-169.

Zuleta, Emilia de (1983). Relaciones literarias entre España y la Argentina. Madrid: Ediciones Cultura Hispánica.

Zuleta, Emilia de (1999). Españoles en la Argentina: el exilio literario de 1936. Buenos Aires: Atril. 


\section{Fondos documentales}

Archivo de la Fundación Luis Seoane (A Coruña).

\section{Fuentes primarias}

Correo Literario. Buenos Aires, n. ${ }^{\text {os }} 1$ a 40 (noviembre de 1943 - septiembre de 1945).

De Mar a Mar. Buenos Aires, n. ${ }^{\text {os }} 1$ a 7 (diciembre de 1942 - junio de 1943).

Sur. Buenos Aires, n. ${ }^{\text {os }} 105$ a 110 (julio de 1943-diciembre de 1943). 